\title{
New records of Xenanoetus species (Astigmata: Histiostomatidae) in Western Europe, and their association with pig carcasses
}

\author{
Medjedline Hani $^{1}$ (D) . Marta I. Saloña-Bordas ${ }^{2}$ (D) $\cdot$ M. Alejandra Perotti ${ }^{1}$ (D)
}

Received: 11 September 2021 / Accepted: 15 December 2021 / Published online: 7 February 2022

(c) The Author(s) 2022

\begin{abstract}
The genus Xenanoetus Mahunka, 1969, only described by the hypopial stage, is characterised by an enlarged gnathosoma, the presence of double claws in legs I, II and III in addition to remarkably broadened femur and genu of legs I and II, particularly visible in lateral view. Only five species from this genus have been described and they are all from the northern hemisphere. Hypopi are generally found as phoretic on Sphaeroceridae flies and Hydrophilidae beetles. Until present, hypopi of the species Xenanoetus grandiceps have only been reported in Mongolia, described by Mahunka in 1973. Xenanoetus grandiceps is characterised by the presence of a pair of arches pointing anteriorly in the posterior part of the gnathosoma. Here we report for the first time $X$. grandiceps in Spain, and for the second time $X$. vestigialis. Both species were found in association with carcass remains, as phoretic on lesser dung flies (Sphaeroceridae), which were collected in a mixed deciduous forest near the Atlantic coast. Additional new information on morphological characteristics of these Xenanoetus species, as well as habitat requirements and biology are presented in this report.
\end{abstract}

Keywords Myianoetinae $\cdot$ Carrion $\cdot$ Phoresy $\cdot$ Revision $\cdot$ Xenanoetus vestigialis $\cdot$ Xenanoetus grandiceps

\section{Introduction}

Xenanoetus is a genus of Myanoetinae (Histiostomatidae, Sarcoptiformes), a subfamily of astigmatid mites, strictly associated with dung flies and beetles. Under stressful conditions, Histiostomatidae mites moult into a modified deutonymph known as hypopus, an adaptation to phoresy on flying insects for securing transportation to more favourable environmental conditions (Hughes 1976; Braig and Perotti 2009). Hypopi present structures adjusted to phoresy such as ventral suckers that are modified to enable their attachment to their carriers, frequently insects (Hughes 1976; Braig and Perotti 2009). Once detached from the carrier, they moult into the next instar and continue their life cycle under optimal environmental conditions. The lack of knowledge on adult forms of many members of the Histiostomatidae has

M. Alejandra Perotti

m.a.perotti@ reading.ac.uk

1 Ecology and Evolutionary Biology, School of Biological Sciences, University of Reading, Reading, UK

2 Department of Zoology and Animal Cell Biology, University of the Basque Country, UPV/EHU, Bilbao, Spain prompted the use of the phoretic instar for species identification (Hughes 1976; Fain 1984; Samšiňák 1989).

This is the case of Xenanoetus hypopi, whose species have only been described based on the heteromorphic deutonymph. Xenanoetus hypopi have double claws as Myonetinae and can easily be recognised by their broaden gnathosome (=palposome) and their enlarged femur and genu of legs I and II (Mahunka 1969; Fain 1984; Samšiňák 1989). Until present, only five species of this genus are known and only by the phoretic hypopus. Samšiňák (1989) included this species in the review of mites associated with Sphaeroceridae flies. In Europe, only one species from Hungary has been described, which is X. vestigialis Mahunka, 1969.

The five known species are phoretic on dung flies (Sphaeroceridae, Diptera) and dung beetles (Hydrophilidae, Coleoptera). Sphaeroceridae are small flies considered to be coprophilous (Samšiňák 1989). Hydrophilidae are aquatic beetles that have been reported to be associated with submerged carcasses (Hobischak 1997; Cazorla Perfetti and Morales Moreno 2019). In recent years, the increasing number of research projects addressing mammal decomposition, using pig carcass remains, often reported the presence of Sphaeroceridae flies and Hydrophilidae beetles as components of the scavenging terrestrial fauna (Castillo Miralbés 
2002; García-Rojo 2004; Tabor et al. 2005; Martinez et al. 2007; Eberhardt and Elliot 2008; Matuszewski et al. 2008; Al-Mesbah et al. 2012; Horenstein et al. 2012; Arnaldos et al. 2014; Diaz Martín and Saloña-Bordas 2015; among others), and this also includes the Basque Country (North of Spain), where sampling took place. Their presence on a carcass environment may be accidental but highlights the lack of knowledge on the micro-sarcosaprophagous fauna. The phoretic mites transported by this overlooked insect fauna are even less known (Perotti and Braig 2009).

After the description of X. vestigialis Mahunka, 1969 from Hungary, new reports recorded the mites associated with Sphaeroceridae, which were collected in a water trap in England (Ostoja-Starzewski 1999) and in a sub-desert environment in the north of Spain (Pedrochi Renault 1998; Blasco Zumeta and Melic 1999; Iraola 1999); unfortunately, these voucher specimens were not available for study. The second species included in this review, $X$. grandiceps, has not yet been recorded since its original description from Mongolian steppes (Mahunka 1973). In both species, new morphological characteristics and habitat conditions were observed and presented here.

\section{Material and methods}

Ten pig carcasses (Sus scrofa L., 1758) were deposited on the soil of a mixed deciduous forest with pine trees. The carcasses were protected by a metallic cage and observed over a period of 12 weeks; five of the carcasses were positioned in the early summer of 2009 , and the other five replicates were studied in the summer of the consecutive year. Methodology and insects collected have been detailed by Diaz Martín and Saloña-Bordas (2015). Collected insects, for this work: lesser dung flies (Diptera, Sphaeroceridae) recorded as "Dip" were carefully inspected under a stereomicroscope to check for the presence of phoretic mites attached to the surface. Mites were detached from the carrier with a micro dissection needle, hypopi were cleared in lactic acid $(50 \% \mathrm{v} / \mathrm{v})$ and permanently mounted on glass slides in Hoyer's medium for further microscopic analysis (Krantz 1978). Morphological nomenclature follows Hughes (1976), Mahunka (1969, 1973), and Fain (1984).

\section{Results}

Five hypopi were isolated from lesser dung flies (Sphaeroceridae) recorded as Dip 20, Dip 32, and Dip 51. Sphaeroceridae flies were attracted to pig carcasses on day 3 (Dip 51) and day 13 (Dip 20, Dip 32) after deceased; therefore, the carcasses were at the fresh stage for Dip 51 and advanced stage of decomposition for Dip 20 and Dip 32. Hypopi were compared with paratype HMNH- 1448 and HMNH-1459 for $X$. grandiceps and $X$. vestigialis respectively, type series; following Mahunka's reference collection deposited in the Hungarian Natural History Museum, Budapest, Hungary. An illustration of the sucker plates in both species is presented in Fig. 1a-d. Both paratypes and the specimens from North Spain show differences between each other as well as with the original descriptions. Comparative data are summarised in Online Resource: Table S1.

Xenanoetus grandiceps is characterised by a propodosoma abruptly narrowed at the basis, increasing the slope towards the front, following an S-shape (Fig. 2a, b), and a pair of arches anteriorly pointed in the gnathosoma (Fig. 2c, d). Basis of these arches run parallel and on top of them appears a sclerotised triangular structure present in specimens from the Basque country only (Online Resource: Fig. S1). The gnathosoma is longer than broad (L:W 1.23-1.25) and between its terminal hairs, emerging chelicerae are observed (Online Resource: Fig. S2). The surface of the body and the coxisternal region is covered with fine dots (see Online Resource: Fig. S3 for X. vestigialis, which also displays this pattern).

In contrast to the original description, a large suctorial plate (SP) is observed in specimens of $X$. grandiceps collected from the Basque country (Fig. 1a), bearing two large, serrated, functional suctorial discs and 6 well developed conoides, with the 4 medial ones being straight and anteriorly directed, while the 2 lateral ones are slightly curved (Figs. 1a and 2e). In paratype HMNH- 1448 only 4 conoides are present and immerge from a $U$-shaped groove (Figs. 1b and 2f). Additional dissimilarities were observed in the positioning of setae found in genu I. Although smaller, some specimens are in the range of the type series, being $210-227 \mu \mathrm{m}$ in length and 143-146 $\mu \mathrm{m}$ in width.

Xenanoetus vestigialis from the Basque country is bigger than the paratype HMNH-1459 (Online Resource: Table S1) and has a broader gnathosoma. In all specimens the gnathosoma is fully covered by the propodosoma (Fig. 3a-g, $\mathrm{b}-\mathrm{h}, \mathrm{c}-\mathrm{i})$. Lateral margins of the gnathosoma run slightly divergent, both in the paratypes and in the Basque specimens (Fig. 3d, e, f) and not parallel, as outlined by Samšiňák (1989). The imminent genital slit (Fig. 1c, d) is large and the region is piriform with one pair of plates forming each valve (Fig. $3 \mathrm{~m}$ ); from each valve emerge what appears to be a pair of spines (Fig. $3 \mathrm{~m}$ ). The suctorial region (plate) is enfolded anteriorly by flanking plates (Figs. 1c, d and $3 \mathrm{~m}$ ) and laterally, by ligaments emerging from or fusing to the edges of the $U$-shaped groove, running adjacently to the discs. The ends of both structures appear to be fusing to the posterior region of the coxae of the fourth pair of legs. These observations may lead to the assumption that the suctorial region, enclosing the discs and the conoides can be controlled by the movement of legs IV. Similar characteristics, 
Fig. 1 Xenanoetus spp. Comparison of suctorial plates of Xenanoetus grandiceps Mahunka, 1973: a from the Basque Country and b paratype; and of Xenanoetus vestigialis Mahunka, 1969: c from the Basque Country and $\mathbf{d}$ paratype. DI - suctorial discs. $\mathrm{CO}$ - conoides. GO - incipient genital opening. AO - emergent anal opening. LG - ligaments. GRO - groove. FP - flanking plates. Scale bar $20 \mu \mathrm{m}$

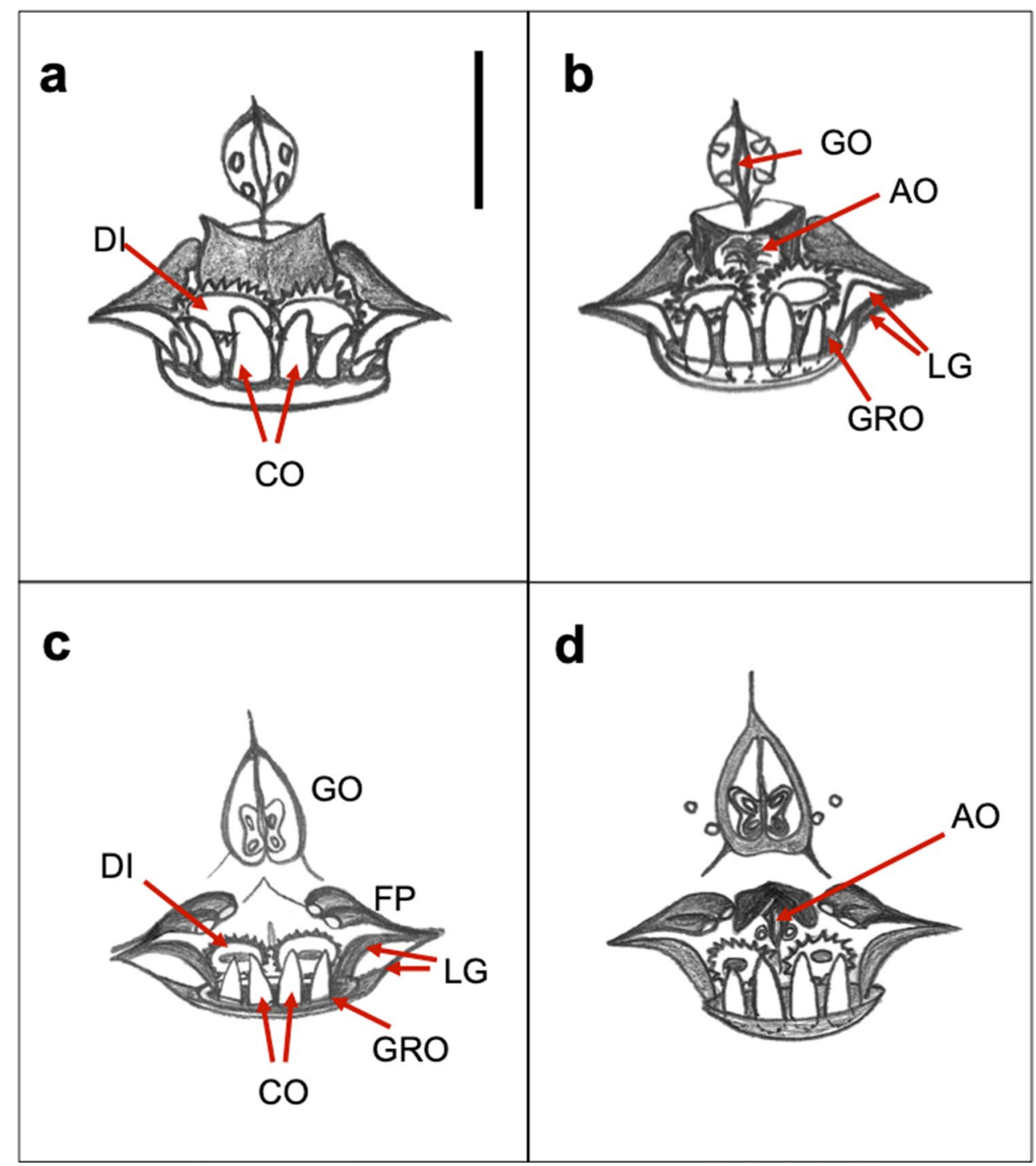

although less clear, were observed in the suctorial plates of $X$. grandiceps specimens. The suctorial plate (SP) therefore, is delimited by discontinuous sort of plates; a pair of suctorial discs is located in the anterior region of the suctorial plate and their borders are serrated. Moreover, between the discs, an incipient potential anal aperture is perceived (Online Resource: Fig. S4), and 4 conoides emerging from $\mathrm{a} U$-shaped groove in the Basque specimens (Figs. $1 \mathrm{c}$ and $3 \mathrm{k}$, 1) and, again 4 conoides are seen in the paratypes (Figs. 1d and $3 \mathrm{j}$ ). In the original description only 8 suctorial disks were mentioned (arranged $2 \mathrm{~min}+2$ large +4 medium sized) (Online Resource: Table S1).

Additional differences are observed in the relative position of the propodosomal setae. Sce setae are not aligned and longer in Basque specimens (Fig. 3h, i) in comparison to the paratype (Fig. 3g). Setae sci are different in shape to the original description and to the studied paratypes from Hungary, instead of setiform, they appear to be smooth and tapering (Fig. 3h). The distance between sce and sci setae is larger in the pararypes than in the Basque population (Fig. 3g, h, i). In addition, two pores or alveoli were observed at the basis of the propodosoma near the dorsosejugal groove in one specimen (Online Resource: Fig. S3). These pores might have become visible as a result of excess of pressure performed during the mounting process, as they were not noted by Mahunka in the original description.

Mites found in the Basque country arrived early on the carrier to the decomposing carcass at a fresh stage of decomposition, on day 3 after death.

\section{Discussion}

Xenanoetus species are known to have established a close association with lesser dung flies (Samšiňák 1989). Both mite species were found on Sphaeroceridae from the research 
Fig. 2 Xenanoetus grandiceps Mahunka, 1973, comparative anatomy of paratype 1448 and Basque specimens. a Basque specimen dorsal view; b paratype ventral view; c Basque specimen gnathosoma; d paratype 1448 gnathosoma; e Basque specimen suctorial plate and incipient genital opening; f paratype 1448 suctorial plate and incipient genital opening. Scale bars $100 \mu \mathrm{m}(\mathbf{b}), 20 \mu \mathrm{m}(\mathbf{d}, \mathbf{f})$

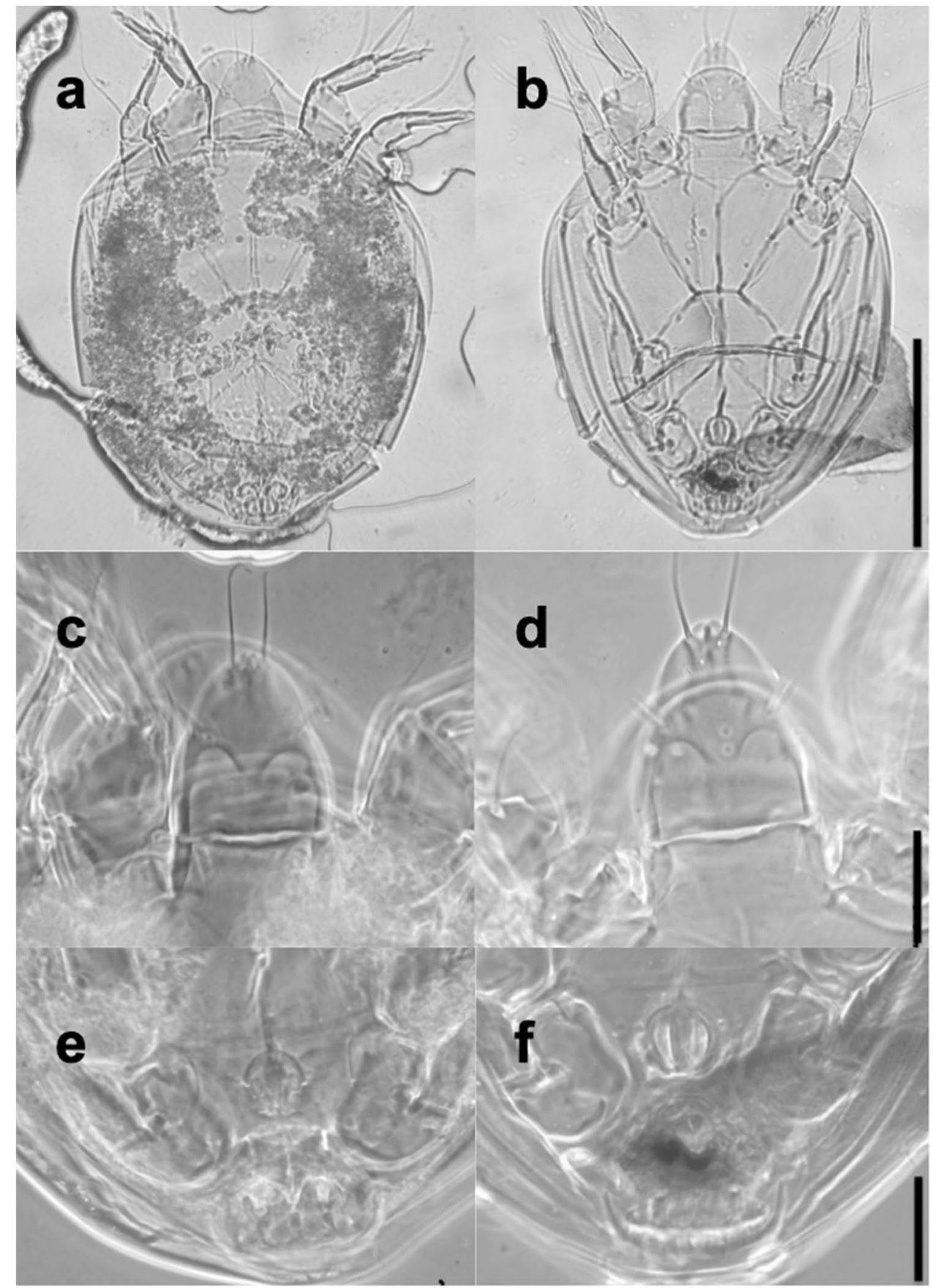

conducted in Aiako Harria (Gipuzkoa, Spain). Similarly, in England, the mite has been found on Coproica acutangula (Zetterstedt, 1847) (Diptera, Sphaeroceridae) (OstojaStarzewski 1999). Nevertheless, both species described by Mahunka were collected from dung associated arthropods other than dung flies; the beetle Sphaeridium (Coleoptera, Hydrophilidae) and the insect Hydroetia meleagris Duft. captured by Dr. P. Somogyi in Ulan-Baator (Mongolia). For this work, it was not possible to confirm the identity of this species, H. meleagris, and we assume that there is a possible misspelling or synonymy, which we could not find. A revision of the potential identity of this elusive host suggests that the author might have proposed a moth, Hydroecia, a synonymous of Gortyna (Noctuidae, Lepidoptera) a pest in cultures ( $c f$ FAO). However, no species of Hydroecia is connected to the author Duft.

Basque specimens show differences with the original description including the shape and location of the propodosomal setae, as well as larger suctorial plates (SP) in $X$. vestigialis, and a variable number of conoids, a sclerotized 


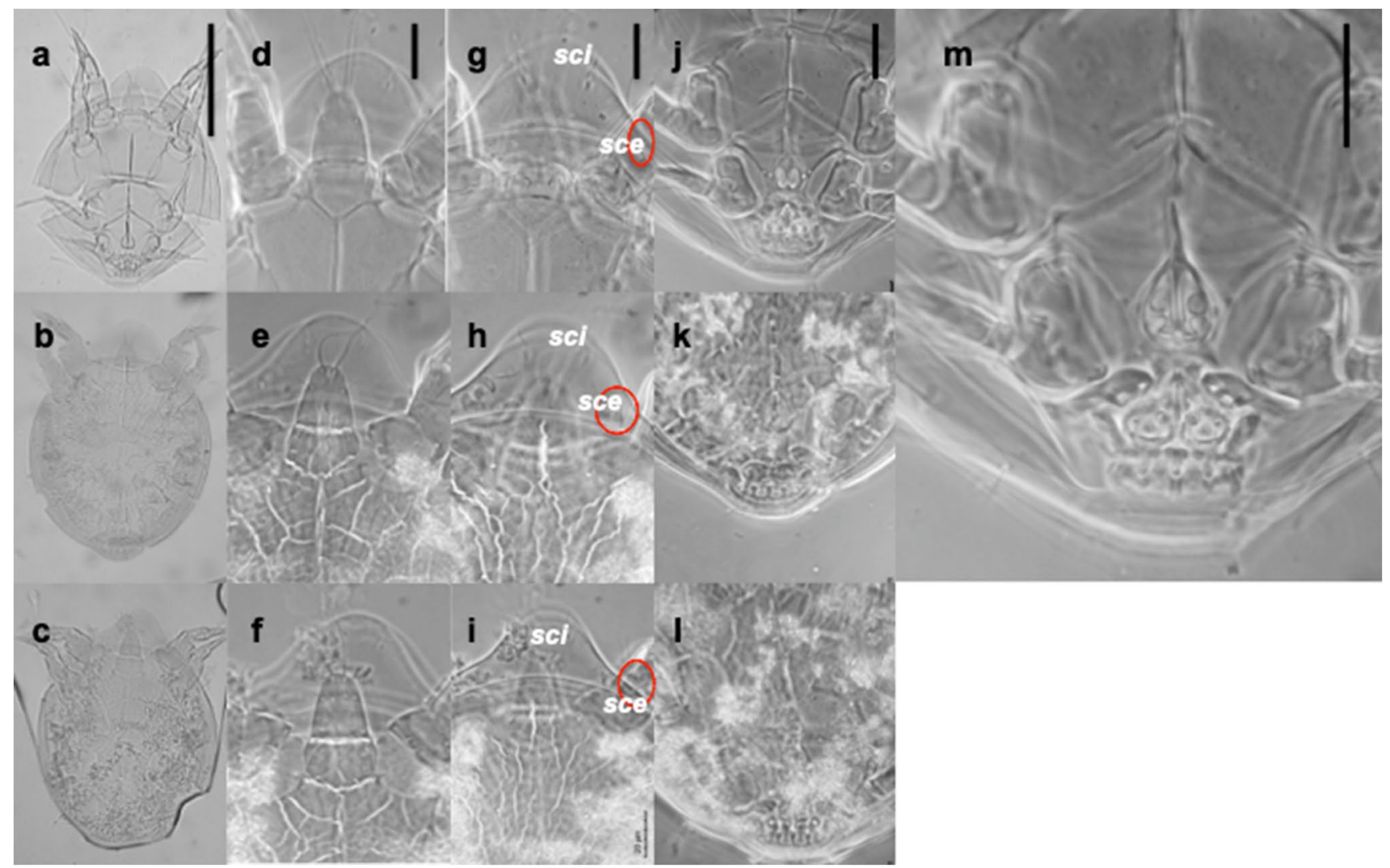

Fig. 3 Xenanoetus vestigialis Mahunka, 1969, comparative anatomy of paratype 1459 and two Basque specimens 1 and 2. a Paratype 1459 ventral view; b Basque specimen 1 dorsal view; c Basque specimen 2 dorsal view; d paratype 1459 gnathosoma; e Basque specimen 1 gnathosoma; f Basque specimen 2 gnathosoma; g paratype 1459 propodosoma with details of setae $s c i$ and $s c e ; \mathbf{h}$ Basque specimen 1

region on the gnatosoma in addition to incipient chelicerae are observed between the terminal setae of the gnatosoma in $X$. grandiceps. In both species, flanking plates and ligaments were observed around the discs and fused to the lateral sides of the groove on one end, and to the posterior region of coxae IV on the other end; enclosing the suctorial region. The flanking plates and ligaments might be used for the functional movement of discs and conoides. The mites are possibly able to control them by moving their fourth pair of legs. An additional incipient aperture was observed between the discs, which might develop later into the anal opening.

Due to their minute size as well as the lack of research on phoronts and their carriers, these mites and their hypopi are frequently overlooked. For many species of mites associated with animal decomposition, only the phoretic instars have been described and the other stages remain unknown, as is the case for Xenanoetus species (Mahunka 1969, 1973; Samšiňák 1989). Moreover, habitat requirements are rarely detailed in the description of new species. Here we expand the habitat characteristic of both mite species, that can be found either in arid (Mongolian and Monegros steppes) or in propodosoma with details of setae sci and sce; i Basque specimen 2 propodosoma with details of setae $s c i$ and $s c e$; $\mathbf{j}$ paratype 1459 suctorial plate and incipient genital opening; $\mathbf{k}$ Basque specimen 1 suctorial plate and incipient genital opening; 1 Basque specimen 2 suctorial plate; m paratype 1459 suctorial plate and incipient genital opening. Scale bars $100 \mu \mathrm{m}(\mathbf{a}), 20 \mu \mathrm{m}(\mathbf{d}, \mathbf{g}, \mathbf{j}, \mathbf{m})$

highly humid environments (humid forests in Hungary and Spain and a water trap in England).

Is there something in common in such disparate environments? Sphaeroceridae flies are considered coprophilous and can be found in larger numbers during the process of decomposition. These flies might be associated with coprophagous animals that visit the carcasses using sarcosaprohagous arthropods as phoronts (Marshall 2012). Larvae develop in humid environments such as dung, carrion and other decaying remains (Marshall 2012). These ephemerous environments are common in decomposing carcasses and in ponds where decaying matter accumulates on the surface leading to the attraction of coprophilous insects.

Flies are amongst the first to arrive during decomposition whereas, Coleoptera may be accidental hosts of Xenanoteus that uses the beetles to depart and leave the carcass possibly looking for a new source of food and establishing new colonies, once the cycle is completed. Only five hypopi were collected from three carriers at two particular occasions during the decomposition process, at fresh stage, perhaps brought by the flies themselves, 
and at advance decay, possibly flies with mites, carried by dung beetles -a case of hyper-phoresy. Therefore, a more in depth research is required to gain knowledge on both mites and their carriers, life cycles, to better understand the habitat requirements of both the insects and their associated phoretic mites.

Our findings confirm the preference of both the flies and their associated mites of humid environments, rich with decaying carrion. Whereas $X$. vestigialis was collected at an early fresh stage of decomposition on D3, X. grandiceps was not collected until day 13 when the carcasses reached the advanced stage of decomposition close to skeletonization. The mites reviewed here, report new additional information to the original descriptions done by Mahunka in 1969 and 1973. Xenanoteus grandiceps remained unrecorded since its first description in 1973 by Mahunka.

Both species of Xenanoetus were found on Sphaeroceridae, which confirms the intimate relationship between these mites and their carriers. All the species from this genus are closely associated with dung flies (Sphaeroceridae, Diptera). These small flies are considered to be coprophilous (Samšiňák 1989). In recent years, an increasing number of research was conducted using carcass remains and frequently reported the presence of Sphaeroceridae (Castillo Miralbés 2002; García-Rojo 2004; Tabor et al. 2005; Martinez et al. 2007; Matuszewski et al. 2008; Eberhardt and Elliot 2008; Al-Mesbah et al. 2012; Horenstein et al. 2012; Arnaldos et al. 2014; Diaz Martín and Saloña-Bordas 2015; among others). Their presence during the decomposition process of carcasses may be accidental but due to their small size, these flies can be overlooked when collecting entomological evidence; explaining the limited knowledge and information on sarcosaprophagous fauna, and therefore their associated mites. Conclusions and assumptions on their biology and distribution should be taken cautiously.

This review contributes with two new records of Xenanoetus hypopi associated with dung flies, which were collected from decomposing carcasses. The first record refers to $X$. vestigialis recently reported from Monegros, a sub-desert environment considered a remnant of the Asian steppes (Pedrochi Renault 1998). The new observation reports the presence of $X$. vestigialis in a temperate and humid forest close to the coast, in the North of Spain, fairly different to the sub-desert environment, where the mite was first collected. Aiako Harria natural park rainfall records exceed $2000 \mathrm{~mm}$ per year (cf. Basque Government 2019), whereas precipitation records in Monegros oscillates between 350 and $451 \mathrm{~mm}$ (cf. Centro de Desarrollo Monegros 2012) and in Mongolian steppes between 100-350 mm per year (Britannica Encyclopaedia 2021).

Supplementary Information The online version contains supplementary material available at https://doi.org/10.1007/s11756-021-00997-2.
Acknowledgements We thank Dr. Csaba from the Hungarian Institute for Forensic Sciences and Dr. Eszter Lazanyi from the Hungarian Natural History Museum for facilitating access and study of the paratypes deposited in the Mahunka's collection (HNHM), in Budapest (Hungary). We also thank Dr. Diaz Martín (Sociedad de Ciencias Aranzadi), who carried out fieldwork and collection of samples; funded by the Basque Government and the University of the Basque Country UPV/ EHU PhD programs.

Authors' contributions Dr. Saloña-Bordas did the literature review needed for the proper identification of the mites. Dr. Hani selected the taxonomic characters and took the pictures that illustrate them. All authors contributed in the redescription of both species.

Funding Dr. Saloña-Bordas was funded by the Spanish Government, Programa de Movilidad de Investigadores "Salvador de Madariaga", Ministerio de Educación, Cultura y Deporte.

Other authors declare that no support was received.

Availability of data and material Material is available for external study. All data gathered is provided in this study.

Code availability Specimens are preserved in slides mounted in Hoyer's fluid and stored with the codes Xve2009Dip51 for Xenanoetus vestigialis, and Xgr09Dip32, Xgr10Dip20 for Xenanoetus grandiceps.

\section{Declarations}

Ethical approval Does not apply.

Informed consent Does not apply.

Conflicts of interest/Competing interests Authors declare no conflict of interest.

Open Access This article is licensed under a Creative Commons Attribution 4.0 International License, which permits use, sharing, adaptation, distribution and reproduction in any medium or format, as long as you give appropriate credit to the original author(s) and the source, provide a link to the Creative Commons licence, and indicate if changes were made. The images or other third party material in this article are included in the article's Creative Commons licence, unless indicated otherwise in a credit line to the material. If material is not included in the article's Creative Commons licence and your intended use is not permitted by statutory regulation or exceeds the permitted use, you will need to obtain permission directly from the copyright holder. To view a copy of this licence, visit http://creativecommons.org/licenses/by/4.0/.

\section{References}

Al-Mesbah H, Moffatt C, El-Azazy OME, Majeed QAH (2012) The decomposition of rabbit carcasses and associated necrophagous Diptera in Kuwait. Forensic Sci Int 217(1-3):27-31. https://doi. org/10.1016/j.forsciint.2011.09.021

Arnaldos MI, Ubero-Pascal N, García R, Carles-Tolrá M, García MD (2014) The first report of Telomerina flavipes (Meigen, 1830) (Diptera, Sphaeroceridae) in a forensic case, with redescription of its pupa. Forensic Sci Int 242:e22-e30. https://doi.org/10.1016/j. forsciint.2014.07.023 
Basque Government (2019) Aiako Harria - Parques Naturales. Departamento de Desarrollo Económico e Infrastructuras. http://www. euskadi.eus. Accessed 10 Dec 2019

Blasco Zumeta J, Melic A (1999) Síntesis sobre la biocenosis de Los Monegros. Boln SEA 24:29-48

Braig H, Perotti MA (2009) Carcasses and mites. Exp Appl Acarol 49(1-2):45-84. https://doi.org/10.1007/s10493-009-9287-6

Britannica Encyclopaedia (2021) Mongolia. Climate and Soils. https://www.britannica.com/place/Mongolia/Climate-and-soils. Accessed 7 Mar 2021

Castillo Miralbés M (2002) Estudio de la Entomofauna asociada a cadáveres en el Alto Aragón (España). Monografías SEA 6, Sociedad Entomológica Aragonesa, Zaragoza

Cazorla Perfetti D, Morales Moreno P (2019) Registro de tres especies de coleópteros acuáticos (Coleoptera: Hydrophilidae y Dytiscidae) en la ciudad de Coro, estado Falcón, Venezuela. Rev Nicaragüense Entomol 185:3-30

Centro de desarrollo Monegros (2012) Proyecto Monegros. http://proye ctomonegros.com/precipitacioncambioclimatico/. Accessed 10 Dec 2019

Diaz Martín B, Saloña-Bordas MI (2015) Arthropods of forensic interest associated to pig carcasses in Aiako Harria Natural Park (Basque Country, Northern Spain). Ciencia Forense 12:207-228

Eberhardt TL, Elliot DA (2008) A preliminary investigation of insect colonisation and succession on remains in New Zealand. Forensic Sci Int 176:217-223. https://doi.org/10.1016/j.forsciint.2007.09. 010

Fain A (1984) Nouveaux hypopes de Myianoetinae provenant de crottes d'éléphants au Rwanda (AcariAnoetidae). Rev Zool Afr 98:279-292

García-Rojo AM (2004) Estudio de la sucesión de insectos en cadáveres en Alcalá de Henares (Comunidad Autónoma de Madrid) utilizando cerdos domésticos como modelos animales. Boln SEA 34:263-269

Hobischak NR (1997) Freshwater invertebrates succession and decompositional studies on carrion in British Columbia. Master's thesis in Pest Management, Simon Fraser University, Burnaby

Horenstein MB, Rosso B, García MD (2012) Seasonal structure and dynamics of sarcosaprophagous fauna on pig carrion in a rural area of Cordoba (Argentina): Their importance in forensic science. Forensic Sci Int 217:146-156. https://doi.org/10.1016/j. forsciint.2011.10.043
Hughes AM (1976) The mites of stored food and houses. Technical Bulletin Agriculture Fisheries \& Food, London

Iraola V (1999) Una aproximación a los ácaros de Monegros. Boln SEA 24:121-124

Krantz GW (1978) A manual of acarology. Oregon State University Book Stores, Oregon

Mahunka S (1969) Xenanoetus vestigialis gen. n., sp. n., and two new species of the genus Myianoetus Oudemans, 1913 (Acari: Anoetoidea). Ann Hist Nat Mus Natl Hung 61:359-362

Mahunka S (1973) Xenanoetus grandiceps sp. n., sowie weitere Angaben über die Anoetidenfauna der Mongolei (Acari). Folia Entomol Hung 26:57-63

Marshall SA (2012) Flies. The natural history and diversity of Diptera. Firefly Books Ltd., New York

Martinez E, Duque P, Wolff M (2007) Succession pattern of carrionfeeding insects in Paramo, Colombia. Forensic Sci Int 166:182189. https://doi.org/10.1016/j.forsciint.2006.05.027

Matuszewski S, Bajerlein D, Konwerski S, Szpila K (2008) An initial study of insect succession and carrion decomposition in various forest habitats of Central Europe. Forensic Sci Int 180:61-69. https://doi.org/10.1016/j.forsciint.2008.06.015

Ostoja-Starzewski J (1999) Xenanoetus vestigialis Mahunka (Acari, Anoetidae) new to Britain, associated with Coproica acutangula (Zett.) (Dipt., Sphaeroceridae). Entomol Month Magaz 135:143-144

Pedrochi Renault, C. coord (1998) Ecología de Los Monegros. La paciencia como estrategia de supervivencia. Instituto de Estudios Altoaragoneses y Centro de Desarrollo de Monegros, Huesca

Perotti MA, Braig HR (2009) Phoretic mites associated with animal and human decomposition. Exp Appl Acarol 49:85-124. https:// doi.org/10.1007/s 10493-009-9280-0

Samšiňák K (1989) Mites on flies of the family Sphaeroceridae. II. Acarologia 30:85-105

Tabor KL, Fell RD, Brewster CC (2005) Insect fauna visiting carrion in Southwest Virginia. Forensic Sci Int 150:73-80. https://doi.org/ 10.1016/j.forsciint.2004.06.041

Publisher's note Springer Nature remains neutral with regard to jurisdictional claims in published maps and institutional affiliations. 